\title{
A SUSTENTABILIDADE NO ENSINO DE DESIGN EM INSTITUIÇÕES FEDERAIS DE ENSINO SUPERIOR NO BRASIL
}

\author{
SUSTAINABILITY IN DESIGN EDUCATION IN FEDERAL HIGHER INSTITUTIONS IN BRAZIL
}

\section{Eliana Paula Calegari, M.Sc. (UFRGS) \\ Branca Freitas de Oliveira, Dra. (UFRGS)}

\author{
Palavras Chave \\ Ensino do design; Sustentabilidade; Instituições Federais de Ensino Superior
}

\section{Key Words}

Design education; Sustainability, Federal Institutions of Higher Education

\section{RESUMO}

Este estudo tem como objetivo analisar a inserção dos aspectos relacionados à sustentabilidade nos cursos de design em Instituições Federais de Ensino Superior no Brasil. Dessa forma, apresenta-se a identificação das Instituições Federais de Ensino Superior que possuem cursos na área de design, realizada através da plataforma e-MEC no período de outubro de 2015. A partir disso, foi realizado o levantamento da estrutura curricular das disciplinas que abordam a sustentabilidade, através do site das universidades, e por meio das ementas foi realizada a análise de conteúdo visando diagnosticar como ocorre a abordagem da sustentabilidade nos cursos de design. A pesquisa revelou que nas ementas dos cursos de design, que abordam disciplinas sobre a sustentabilidade, o ensino é baseado na problemática ambiental, abordando questões como o respeito ao meio ambiente, a qualidade de vida, a consciência ambiental, a preservação dos recursos naturais e impactos ambientais, e, além disso, são apresentadas estratégias de ecodesign a fim de minimizar impactos ambientais provocados durante o ciclo de vida dos produtos.

\section{ABSTRACT}

This study aims to analyze the inclusion of issues related to sustainability in design courses in Federal Institutions of Higher Education in Brazil. Thus, it is presented the identification of Federal Institutions of Higher Education that have courses in design, performed through of the platform e-MEC in October 2015 period. From there, the research of the curriculum of courses that approach sustainability was carried out through the website of the universities and through the menus it was conducted a content analysis aimed at diagnosing how the approach of sustainability in design courses is done. The research revealed that in the menus of design courses that approach subjects of sustainability, teaching is based on environmental problem, addressing issues such as respect for the environment, quality of life, environmental awareness, preservation of natural resources and environmental impacts, and, moreover, are presented ecodesign strategies to minimize environmental impacts during the life cycle of products. 


\section{INTRODUÇÃO}

Atualmente a preocupação com a destruição do meio ambiente tem gerado discussões em torno do desenvolvimento sustentável. O conceito de desenvolvimento sustentável foi abordado pela primeira vez na Conferência Intergovernamental pelo Uso Racional e Conservação da Biosfera da Organização das Nações Unidas para Educação, Ciência e Cultura (UNESCO), com a seguinte definição: "desenvolvimento capaz de suprir as necessidades da geração atual, sem comprometer as gerações futuras, englobando soluções que unem o economicamente viável ao ecologicamente correto e socialmente equitativo." Este conceito foi à base para a Conferência das Nações Unidas pelo Desenvolvimento e Meio Ambiente (UNCED), a Eco-92, que ocorreu no Rio de Janeiro em 1992, sendo referência fundamental do Quinto Plano de Ação da União Europeia para o Ambiente.

Neste contexto, pode-se afirmar que a sustentabilidade é a condição que permite a sobrevivência de todas as formas de vida, proporcionando uma vida segura, saudável e produtiva, em harmonia com a natureza e com os valores culturais e espirituais. Para isso, a Organização das Nações Unidades (ONU) sugere que os povos trabalhem em conjunto para mitigar o consumo global de recursos naturais e energéticos, e amenizar a degradação promovida pela ação humana no meio ambiente (SANTOS, 2010).

Para Sahtouris (2009) a sustentabilidade não abrange somente a esfera ambiental, pois repercute em três planos, a saber: implica uma compreensão do ser, provoca a reflexão da maneira como cada indivíduo pensa e age em relação a si mesmo e aos outros, e orienta o modo que se produz e oferece produtos e serviços. Dessa maneira, a sustentabilidade é tratada de forma holística, em que um plano está relacionado ao outro. Moacir Gadotti (2008) destaca que a vida sustentável trata-se de um modo de vida de bem-estar e de bem viver para todos, em harmonia com o meio ambiente, ou seja, um modo de vida justo, produtivo e sustentável, conforme Gadotti:

Hoje, tomamos consciência de que o sentido das nossas vidas não está separado do sentido que construímos do próprio planeta. Diante da degradação das nossas vidas no planeta, chegamos a uma verdadeira encruzilhada entre um caminho tecnozóico, que coloca toda a fé na capacidade da tecnologia de nos tirar da crise ambiental sem mudar nosso estilo poluidor e consumista de vida, e um caminho ecozóico, fundado em uma nova relação saudável com o planeta, reconhecendo que somos parte do mundo natural, vivendo em harmonia com o universo, caracterizado pelas atuais preocupações ecológicas (GADOTTI, p. 76, 2008).

Com o surgimento do estilo de vida urbano surgiu a sensação de que estamos vivendo descolados da natureza, no entanto, tudo que habita e é construído faz parte do planeta. As cidades, florestas e todos os lugares e biomas fazem parte do planeta, e assim, todas as ações humanas sobre a natureza, que ocorrem em lugares distintos no planeta, repercutem no todo, como ocorre com o aquecimento global que foi acentuado após a Revolução Industrial, que por conta dele presenciamos o aumento da temperatura global, e desastres naturais. Em decorrência do estilo de vida urbano e consumista, que requer grande quantidade de recursos e energia do planeta, há exploração excessiva dos recursos naturais, gerando, por conta disso o desequilíbrio ambiental.

O design é uma atividade ligada com a produção de bens de consumo, que procura satisfazer necessidades de usuários, abordando questões como ergonomia, estética, materiais e outras. Por vezes, o design é percebido como alvo de estímulo do consumo, mas, por outro lado, o design pode ser um aliado da sustentabilidade na medida em que são utilizadas técnicas e ferramentas voltadas para diminuir impactos ambientais em todo o ciclo de vida do produto, como: ecodesign, green design, design for environment. Essa relação do design com a sustentabilidade é de extrema importância, pois, é evidente que dificilmente o consumo irá diminuir, assim, torna-se interessante utilizar artifícios que tornem os produtos menos agressivos ao meio ambiente, como é o caso da contribuição do design.

Neste contexto, percebe-se a importância de aliar a sustentabilidade com o design, na medida em que os designers podem partir de seus preceitos para desenvolver produtos que causem menos danos ao planeta. Neste sentido, é fundamental que a sustentabilidade seja abordada durante a formação destes profissionais, para oferecer conhecimento e subsídios para que possam abordá-la em seus projetos. Sendo assim, o presente trabalho aborda a inserção das questões relacionadas à sustentabilidade nos cursos de graduação em design de Instituições Federais de Ensino Superior no Brasil.

Através de pesquisa na plataforma de cadastro de Instituições do Ministério da Educação, o e-Mec, identificaram-se Instituições Federais de Ensino Superior do Brasil, e partir disso, foi possível pesquisar a estrutura curricular dos cursos a fim de verificar se possuem ou não 
disciplinas relacionadas com a sustentabilidade, e por fim, partiu-se para o levantamento das ementas das disciplinas que possuem relação com a sustentabilidade para a análise desta abordagem.

\section{ODESIGNE OENSINO SUPERIOR NO BRASIL}

$O$ ensino formal e institucionalizado do design, de nível superior, somente ocorreu no século $\mathrm{XX}$, a partir de 1919, com a Bauhaus. As formas anteriores de ensino eram realizadas nas Escolas de Ciências, Artes e Ofícios, Arquitetura e Belas Artes, e ainda nas Academias de Ciências, que foram criadas na Europa a partir da Idade Média, que, em parte, procuravam atender às novas necessidades decorrentes da produção de bens materiais. Na prática, os artesãos, artistas, intelectuais e produtores se uniam para atender a essas necessidades das indústrias. Essas iniciativas desenvolveram uma formação educacional, a nível informal, transmitida por meio da relação mestre-aprendiz e baseada no "aprender fazendo", que é característico do período artesanal (DIAS, 2004).

Em relação ao Brasil, por motivos políticos, ocorreu um atraso na institucionalização do ensino superior. Durante o período colonial e imperial não haviam sido criadas universidades, somente 45 anos após a proclamação da República é que começaram a ser implantadas no Brasil. O nacionalismo da era Vargas que deu lugar ao desenvolvimentismo do governo Juscelino Kubitschek, de 1956 a 1961, atraiu o capital estrangeiro, estimulando a implantação das primeiras indústrias de bens de consumo duráveis, e ampliação dos serviços de infraestrutura, como transporte e fornecimento de energia elétrica. Com os investimentos externos e internos, estimulou-se a diversificação da economia nacional, aumentando a produção de insumos, máquinas e equipamentos pesados para mecanização agrícola, fabricação de fertilizantes, criação de frigoríficos, implementação do transporte ferroviário e da construção naval. Neste cenário, no início dos anos 60 , o setor industrial superou a média de crescimento dos demais setores da economia brasileira (DIAS, 2004).

Nesse contexto histórico-cultural, os primeiros cursos de design começaram a ser criados no Brasil, em meados do século XX. Neste período, conforme Wollner (2002), a formação de profissionais ocorria lentamente, em decorrência de vários fatores, como o desentendimento por parte dos empresários sobre a atividade, a cultura da cópia de produtos bem sucedidos no exterior aliada ao desinteresse dos empresários em elaborar e desenhar seus produtos de forma competitiva.
A partir da década de 60, no Brasil, em várias universidades, estimuladas pelo desenvolvimento econômico e pela política de exportação de produtos manufaturados, foram implementados cursos para atender à demanda de profissionais na área tecnológica, entre eles os designers. Nessa década, o design teve como seu marco histórico a criação da Escola Superior de Desenho Industrial (ESDI), no Estado da Guanabara/RJ, no ano de 1962, cujas raízes remontam ao design europeu, especialmente ao design alemão, com destaque para a Bauhaus e a Escola de UIm. A criação da ESDI pode ser compreendida como a decorrência de uma série de fatores políticos, econômicos e sociais, que esteve diretamente ligada à ideologia nacional-desenvolvimentista dos anos 1950, época inserida em um universo de crenças modernistas (HATADANI et al., 2010). No entanto, conforme Niemeyer (2000), nesse período a maioria dos industriais brasileiros não sabiam o que era design, apesar de haver, entretanto, a percepção da importância do ensino do design, pois era evidente a necessidade de gerar mão de obra qualificada para suprir a demanda de projetos de produtos e de comunicação visual advinda do crescimento econômico e industrial.

Em 1975, funcionavam 15 cursos de graduação em design no Brasil, com currículos e métodos de ensino semeIhantes aos da ESDI. A subordinação da indústria nacional ao capital estrangeiro limitou as atividades de criação e desenvolvimento de produtos, resultando na redução de oportunidades de inserção do profissional de Design no meio produtivo. No espaço de dez anos, poucas escolas foram criadas, sendo que em 1985 existiam 19 escolas atuantes no país (DIAS, 2004).

Atualmente, a situação dos cursos de design, conforme o Ministério da Educação (MEC), com base na plataforma e-MEC, em que as Instituições de Educação Superior e os cursos estão cadastrados, no Brasil são ofertados entre 500 e 600 cursos de design, sendo que destes, cerca de 316 cursos são tecnológicos, 257 cursos de Bacharelado, 4 sequenciais e 1 de licenciatura (em design de moda). Cabe destacar, que estes dados não são precisos, pois a plataforma disponibiliza vários formatos de busca e os resultados não são iguais (E-MEC, 2015).

Em relação aos cursos de bacharelado, são destinados para indivíduos que pretendem atuar no mercado de trabalho. Já os cursos de licenciatura são voltados para a formação de professores de ensino fundamental e médio. No que diz respeito aos cursos sequenciais, são descritos como cursos superiores de curta duração, em torno de 2 anos, e os tecnológicos oferecem habilidades específicas em determinadas áreas. 
Nos cursos sequenciais, ao final, o estudante possui diploma de nível superior, mas só pode ingressar na pós-graduação Latu Sensu, não tendo acesso a mestrado e doutorado (BRASIL, 2015). Os cursos tecnológicos, como os de bacharelado são voltados para pessoas que pretendem atuar no mercado de trabalho, com curta duração e foco específico em uma determinada área do conhecimento. Estes cursos são destinados para a inovação e necessidades da sociedade, sendo direcionados ao setor produtivo (VALLEI, 2012).

Os cursos mencionados são ofertados por instituições públicas ou privadas de ensino, sendo que as públicas são mantidas pelo poder público, na forma federal, estadual ou municipal. As privadas são administradas por pessoas físicas ou jurídicas de direito privado, com a finalidade de obter lucro (MINISTÉRIO DAS RELAÇÕES EXTERIORES, 2015). No Brasil, conforme a plataforma e-MEC (2015), 509 cursos de design são oferecidos por instituições privadas e 69 por em instituições públicas.

\section{METODOLOGIA}

Visando a discussão sobre a abordagem da sustentabilidade nos cursos de design nas Instituições Federais de Ensino Superior no Brasil, foi esquematizada a metodologia de pesquisa conforme pode ser visualizada na tabela 1. A escolha por instituiçõos federais deve-se ao fato de que estas disponibilizam em seu site a estrutura curricular e a ementa das disciplinas, o levantamento de dados foi realizado no mês de outubro de 2015.

Tabela 1: Esquematização da metodologia de pesquisa.

\begin{tabular}{|c|c|c|c|}
\hline $\begin{array}{c}\text { Etapas da } \\
\text { pesquisa }\end{array}$ & Objetivo & $\begin{array}{l}\text { Método de } \\
\text { coleta }\end{array}$ & $\begin{array}{l}\text { Método de } \\
\text { análise }\end{array}$ \\
\hline $\begin{array}{l}\text { Levantamento } \\
\text { dos cursos de } \\
\text { design }\end{array}$ & $\begin{array}{l}\text { Identificar as } \\
\text { universidades } \\
\text { Federais que } \\
\text { possuem cur- } \\
\text { so de design }\end{array}$ & $\begin{array}{l}\text { Pesquisa } \\
\text { realizada na } \\
\text { plataforma } \\
\text { e-MEC }\end{array}$ & $\begin{array}{l}\text { Classificação dos } \\
\text { dados conforme } \\
\text { o estado brasi- } \\
\text { leiro, a denomi- } \\
\text { nação do curso } \\
\text { e a Instituição } \\
\text { Federal de Ensino } \\
\text { Superior }\end{array}$ \\
\hline $\begin{array}{l}\text { Levantamento } \\
\text { da estrutura } \\
\text { curricular dos } \\
\text { cursos de } \\
\text { design }\end{array}$ & $\begin{array}{l}\text { Identificar as } \\
\text { disciplinas } \\
\text { que abordam } \\
\text { o ensino da } \\
\text { sustentabili- } \\
\text { dade. }\end{array}$ & $\begin{array}{l}\text { Pesquisa } \\
\text { nos sites das } \\
\text { Universidades } \\
\text { Federais } \\
\text { de Ensino } \\
\text { Superior }\end{array}$ & $\begin{array}{l}\text { Classificação } \\
\text { dos dados de } \\
\text { acordo com a } \\
\text { Universidade, } \\
\text { denominação do } \\
\text { curso, disciplina } \\
\text { que aborda a sus- } \\
\text { tentabilidade, se } \\
\text { é obrigatória ou } \\
\text { optativa, período } \\
\text { e carga horária }\end{array}$ \\
\hline
\end{tabular}

Continua na próxima coluna.
Continuação da Tabela 1

\begin{tabular}{|l|l|l|l|}
\hline $\begin{array}{l}\text { Levantamento } \\
\text { da ementa } \\
\text { das disciplinas }\end{array}$ & $\begin{array}{l}\text { Analisar a } \\
\text { abordagem } \\
\text { da sustenta- }\end{array}$ & $\begin{array}{l}\text { Pesquisa } \\
\text { nos sites das } \\
\text { Universidades }\end{array}$ & $\begin{array}{l}\text { Análise de conte- } \\
\text { údo das ementas }\end{array}$ \\
$\begin{array}{l}\text { o ensino da } \\
\text { sustentabili- } \\
\text { dade. }\end{array}$ & $\begin{array}{l}\text { cursos de } \\
\text { design }\end{array}$ & $\begin{array}{l}\text { Federais } \\
\text { de Ensino }\end{array}$ & \\
Superior & \\
\end{tabular}

A primeira etapa da pesquisa consistiu na identificação das Instituições Federais de Ensino Superior do Brasil que possuem cursos de design, que foi realizada na plataforma e-MEC, em todos os estados brasileiros. A plataforma e-MEC do Ministério da Educação foi desenvolvida para a tramitação eletrônica dos processos de regulamentação e disponibiliza informações sobre as Instituições de Ensino Superior cadastradas. Dessa forma, por meio da internet, as instituições de educação superior podem realizar o credenciamento e o recredenciamento, buscam autorização, reconhecimento e renovação de reconhecimento de cursos (E-MEC, 2015). Os dados coletados na plataforma e-MEC foram organizados segundo o estado onde se encontra a Instituição, a denominação do curso e a Instituição Federal de Ensino Superior.

Na segunda etapa da investigação, realizou-se uma pesquisa na internet nos sites das Universidades Federais de Ensino Superior identificadas na plataforma e-MEC, em que se buscou a estrutura curricular dos cursos de design. A análise feita nas grades curriculares encontradas foi em relação à existência de disciplinas voltadas ou que abordam o ensino das questões da sustentabilidade no design. Dessa forma, foram coletados os dados referentes à denominação da disciplina, se é obrigatória ou optativa, o período do curso em que é ofertada e a carga horária da disciplina.

A terceira etapa consistiu no levantamento das ementas dos cursos de design nos sites das Universidades. Dessa forma, puderam-se analisar as ementas das disciplinas que possuem relação com a temática da sustentabilidade através da análise de conteúdo, sendo assim, foi possível verificar a abordagem deste assunto nos cursos de design. Segundo Bardin (2011, p.46) a análise de conteúdo consiste em uma operação de "classificação de elementos constitutivos de um conjunto por diferenciação e, em seguida, por reagrupamento segundo o gênero (analogia), com os critérios previamente definidos", o que permitiu a condensação e a representação simplificada dos dados brutos encontrados.

Para o tratamento dos dados foi utilizado o programa RQDA (R Package for Qualitative Data Analysis) a fim de auxiliar o processo de análise dos mesmos. Após a coleta dos dados, foi iniciado o processo de classificá-los em 
subcategorias. As subcategorias são palavras ou pequenos grupos de palavras que são definidas a partir da frequência em que aparecem nos dados, além da maior representatividade (BARDIN, 2011). A partir do agrupamento dos dados, foi possível interpretar os resultados e caracterizar a abordagem da sustentabilidade nos cursos de design de Instituições Federais de Ensino Superior do Brasil.

\section{O ENSINO DA SUSTENTABILIDADE NOS CURSOS DEDESIGNEM INSTITUIÇÕESDE ENSINO SUPERIOR NO BRASIL}

\subsection{Identificação das Universidades Federais que possuem cursos de Design}

Foi realizada uma pesquisa na plataforma e-MEC para identificar as Instituições de Ensino Superior que possuem cursos de design no Brasil, e os resultados são apresentados a partir das regiões brasileiras, nas tabelas 2, 3, 4, 5 e 6. Nota-se que na região Norte do Brasil existem, atualmente, 4 Universidade Federais com cursos de design, na Região Nordeste há 7 Universidades Federais com cursos de design, na Região Centro-Oeste são 2 Universidades Federais, na Região Sudeste são 7 e na Região Sul do Brasil há 6 Universidades Federais que possuem cursos de design.

Tabela 2: Instituições Federais de Ensino Superior com cursos na área de design da Região Norte do Brasil.

\begin{tabular}{|c|l|l|}
\hline \multicolumn{3}{|c|}{ Região Norte do Brasil } \\
\hline Estado & $\begin{array}{c}\text { Denominação do } \\
\text { curso }\end{array}$ & \multicolumn{1}{|c|}{$\begin{array}{c}\text { Instituição Federal de } \\
\text { Ensino Superior }\end{array}$} \\
\hline SE & Design Gráfico & $\begin{array}{l}\text { Universidade Federal de } \\
\text { Sergipe (UFS) }\end{array}$ \\
\hline AL & Design & $\begin{array}{l}\text { Universidade Federal de } \\
\text { Alagoas (UFAL) }\end{array}$ \\
\hline PB & $\begin{array}{l}\text { Design - Projeto de } \\
\text { Produto }\end{array}$ & $\begin{array}{l}\text { Universidade Federal da } \\
\text { Paraíba (UFPB) / Universidade } \\
\text { Federal de Campina Grande } \\
\text { (UFCG) }\end{array}$ \\
\hline
\end{tabular}

Fonte: E-MEC (2015).

Tabela 3: Instituições Federais de Ensino Superior com cursos na área de design da Região Nordeste do Brasil.

\begin{tabular}{|c|l|l|}
\hline \multicolumn{3}{|c|}{ Região Nordeste do Brasil } \\
\hline Estado & $\begin{array}{c}\text { Denominação do } \\
\text { curso }\end{array}$ & \multicolumn{1}{|c|}{$\begin{array}{c}\text { Instituição Federal de } \\
\text { Ensino Superior }\end{array}$} \\
\hline RN & Design & $\begin{array}{l}\text { Universidade Federal do Rio } \\
\text { Grande do Norte (UFRN) }\end{array}$ \\
\hline $\mathrm{PE}$ & Design & $\begin{array}{l}\text { Universidade Federal de } \\
\text { Pernambuco (UFPE) }\end{array}$ \\
\hline $\mathrm{CE}$ & Design de Produto & $\begin{array}{l}\text { Universidade Federal do } \\
\text { Cariri (UFCA) }\end{array}$ \\
\hline
\end{tabular}

Continua na próxima coluna.
Continuação da Tabela 3.

\begin{tabular}{|c|l|l|}
\hline & Design & $\begin{array}{l}\text { Universidade Federal do } \\
\text { Ceará (UFC) }\end{array}$ \\
\hline & Design de Moda & \\
\hline & Design Digital & $\begin{array}{l}\text { Universidade Federal do } \\
\text { Maranhão (UFMA) }\end{array}$ \\
\hline MA & Design & $\begin{array}{l}\text { Universidade Federal do } \\
\text { Amazonas (UFAM) }\end{array}$ \\
\hline BA & Design & $\begin{array}{l}\text { Universidade Federal da } \\
\text { Bahia (UFBA) }\end{array}$ \\
\hline
\end{tabular}

Fonte: E-MEC (2015)

Tabela 4: Instituições Federais de Ensino Superior com cursos na área de design da Região Centro-Oeste do Brasil.

\begin{tabular}{|c|l|l|}
\hline \multicolumn{3}{|c|}{ Região Centro-Oeste } \\
\hline Estado & \multicolumn{1}{|c|}{$\begin{array}{c}\text { Denominação do } \\
\text { curso }\end{array}$} & $\begin{array}{l}\text { Instituição Federal de Ensino } \\
\text { Superior }\end{array}$ \\
\hline GO & $\begin{array}{l}\text { Desenho Industrial - } \\
\text { Programação Visual e } \\
\text { Projeto de Produto }\end{array}$ & Universidade de Brasília (UNB) \\
\hline & Design Gráfico & $\begin{array}{l}\text { Universidade Federal de Goiás } \\
\text { (UFG) }\end{array}$ \\
\hline & Design de Moda & \\
\hline
\end{tabular}

Fonte: E-MEC (2015).

Tabela 5: Instituições Federais de Ensino Superior com cursos na área de design da Região Sudeste do Brasil.

\begin{tabular}{|c|l|l|}
\hline \multicolumn{3}{|c|}{ Região Sudeste do Brasil } \\
\hline Estado & $\begin{array}{c}\text { Denominação do } \\
\text { curso }\end{array}$ & $\begin{array}{l}\text { Instituição Federal de Ensino } \\
\text { Superior }\end{array}$ \\
\hline MG & Design & $\begin{array}{l}\text { Universidade Federal de Juiz } \\
\text { de Fora (UFJF) / Universidade } \\
\text { Federal de Minas Gerais } \\
\text { (UFMG) / Universidade Federal } \\
\text { de Uberlândia (UFU) }\end{array}$ \\
\hline \multirow{2}{*}{ ES } & $\begin{array}{l}\text { Desenho Industrial - } \\
\text { Programação Visual }\end{array}$ & $\begin{array}{l}\text { Universidade Federal de Minas } \\
\text { Gerais (UFMG) } \\
\text { Espírito Santo (UFES) }\end{array}$ \\
\hline RJ & $\begin{array}{l}\text { Desenho industrial - } \\
\text { Projeto de Produto }\end{array}$ & $\begin{array}{l}\text { Universidade Federal } \\
\text { Fluminense (UFF) / } \\
\text { Universidade Federal do Rio de } \\
\text { Janeiro (UFRJ) }\end{array}$ \\
\hline
\end{tabular}

Fonte: E-MEC (2015)

Tabela 6: Instituições Federais de Ensino Superior com cursos na área de design da Região Sul do Brasil.

\begin{tabular}{|c|l|l|}
\hline \multicolumn{3}{|c|}{ Região Sul do Brasil } \\
\hline Estado & \multicolumn{1}{|c|}{$\begin{array}{c}\text { Denominação do } \\
\text { curso }\end{array}$} & $\begin{array}{l}\text { Instituição Federal de Ensino } \\
\text { Superior }\end{array}$ \\
\hline PR & $\begin{array}{l}\text { Design gráfico - Design } \\
\text { de Produto }\end{array}$ & $\begin{array}{l}\text { Universidade Tecnológica } \\
\text { Federal do Paraná (UTFPR) }\end{array}$ \\
\hline & Design de produto & $\begin{array}{l}\text { Universidade Federal do } \\
\text { Paraná (UFPR) }\end{array}$ \\
\hline & Design Gráfico & \\
\hline
\end{tabular}

Continua na próxima coluna. 
Continuação da Tabela 6.

\begin{tabular}{|l|l|l|}
\hline SC & Design de Produto & $\begin{array}{l}\text { Universidade Federal de Santa } \\
\text { Catarina (UFSC) }\end{array}$ \\
\hline & Design Gráfico & \\
\hline & Design de Animação & \\
\hline RS & Desenho Industrial & $\begin{array}{l}\text { Universidade Federal de Santa } \\
\text { Maria (UFSM) }\end{array}$ \\
\hline & Design de Produto & $\begin{array}{l}\text { Universidade Federal do Rio } \\
\text { Grande do Sul (UFRGS) }\end{array}$ \\
\hline & Design Visual & $\begin{array}{l}\text { Universidade Federal de } \\
\text { Pelotas (UFPEL) }\end{array}$ \\
\hline & Design Gráfico & \\
\hline & Design Digital &
\end{tabular}

Fonte: E-MEC (2015)

Como base nos dados dos quadros citados, foram identificadas 7 habilitações para os cursos de design em Instituições Federais de Ensino Superior: Design Digital, Design Visual, Design de Produto, Design de animação, Design Gráfico, Design de Moda e Programação visual. É possível perceber que todas as regiões possuem Universidades Federais que oferecem cursos de Design, sendo que os cursos presentes em todas as regiões é o Design Gráfico e o Design de Produto, considerando que Programação Visual é similar ao Design Gráfico. $O$ curso mais ofertado é o de Design, que não possui habilitação específica na nomenclatura. A Região Sul é a que apresenta o maior número de cursos de Design em universidades Federais, totalizando 11, e a Região Norte com o menor número de cursos, totalizando 3 .

\subsection{Identificação de disciplinas dos cursos de design que abordam o ensino da sustentabilidade}

Realizou-se uma pesquisa na plataforma e-MEC para identificar a existência de disciplinas que abordam a sustentabilidade em cursos de design em Universidades Federais, os resultados são apresentados na tabela 7. Constatou-se que há disciplinas sobre sustentabilidade nos cursos de design em 12 Universidades Federais Brasileiras. Este número pode estar associado ao fato de que a Resolução № 5, de 8 de março de 2004 do Ministério da Educação (MEC), que estabelece as diretrizes

Tabela 7: Instituições Federais de Ensino Superior que possuem disciplinas com temática sobre sustentabilidade nos cursos de design.

\begin{tabular}{|c|c|c|c|c|c|}
\hline Instituição & Curso & $\begin{array}{l}\text { Disciplina sobre } \\
\text { sustentabilidade }\end{array}$ & $\begin{array}{l}\text { Obrigatória / } \\
\text { Optativa }\end{array}$ & Período & $\begin{array}{l}\text { Carga horária } \\
\text { (horas) }\end{array}$ \\
\hline UFRN & Design & Design Sustentável & Obrigatória & $4^{\circ}$ & 30 \\
\hline UFCA & Design de Produto & Ecodesign & Optativa & $5^{\circ}$ & 64 \\
\hline UFMA & Design & Desenho Ambiental & Optativa & $9^{\circ}$ & 45 \\
\hline UFAM & Design & Ecodesign & Obrigatória & $6^{\circ}$ & 60 \\
\hline \multirow[t]{4}{*}{ UNB } & $\begin{array}{l}\text { Desenho Industrial - } \\
\text { Programação Visual }\end{array}$ & Ciências do Ambiente & Optativa & - & - \\
\hline & & $\begin{array}{l}\text { Conservação de } \\
\text { Recursos Naturais }\end{array}$ & Optativa & - & - \\
\hline & & Ecologia Geral & Optativa & - & - \\
\hline & $\begin{array}{l}\text { Desenho Industrial - Projeto } \\
\text { de Produto }\end{array}$ & Ciências do Ambiente & Optativa & - & - \\
\hline UFG & Design Gráfico & Design Ambiental & Obrigatória & $6^{\circ}$ & 64 \\
\hline \multirow[t]{2}{*}{ UFMG } & Design & $\begin{array}{l}\text { Ecodesign e Meio } \\
\text { Ambiente }\end{array}$ & Optativa & - & 45 \\
\hline & Design de moda & - & - & - & - \\
\hline UFF & $\begin{array}{l}\text { Desenho indutrial - Projeto } \\
\text { de Produto }\end{array}$ & $\begin{array}{l}\text { Engenharia e Meio } \\
\text { Ambiente }\end{array}$ & Obrigatória & $5^{\circ}$ & 60 \\
\hline UFPR & Design de Produto & Design Sustentável & Optativa & - & 60 \\
\hline \multirow[t]{5}{*}{ UFSC } & Design de Produto & Sustentabilidade & Obrigatória & - & 54 \\
\hline & Design Gráfico & Sustentabilidade & Obrigatória & - & 54 \\
\hline & & Análise do Ciclo de Vida & Optativa & - & 36 \\
\hline & Design de Animação & Sustentabilidade & Obrigatória & $3^{\circ}$ & 54 \\
\hline & & $\begin{array}{l}\text { Gestão da } \\
\text { Sustentabilidade }\end{array}$ & Optativa & - & 36 \\
\hline UFSM & Desenho Industrial & Design Socioambiental & Optativa & $3^{\circ}$ & 60 \\
\hline
\end{tabular}


Continuação da Tabela 7.

\begin{tabular}{|l|l|l|l|l|l|}
\hline & & Ecodesign & Optativa & $3^{\circ}$ & 60 \\
\hline UFRGS & Design Visual & Ecodesign & Obrigatória & $2^{\circ}$ & 30 \\
\hline & & Gestão ambiental & Obrigatória & $4^{\circ}$ & 30 \\
\hline & Design de Produto & Ecodesign & Obrigatória & $2^{\circ}$ & 30 \\
\hline & & Gestão ambiental & Obrigatória & $4^{\circ}$ & 30 \\
\hline
\end{tabular}

Fonte:UFRN(2015), UFCA(2015), UFMA(2015), UFAM(2015), UNB(2015), UFG(2015), UFMG(2015), UFF(2015), UFPR(2015), UFSC(2015), UFSM(2015), UFRGS (2015).

curriculares nacionais para os cursos de design, não especificar os conteúdos que devem compor o currículo, atribuindo às Instituições de Ensino Superior, certa autonomia na elaboração dos seus currículos.

A tabela acima revela que nas instituições investigadas a abordagem da sustentabilidade é realizada por meio de disciplinas específicas, que estão alocadas, principalmente, nos cursos com habilitação em produto. Em relação à nomenclatura da disciplina não há uniformidade, predominando Ecodesign e Design Sustentável. Para Selau e Vieira (2014) os cursos superiores em design são oferecidos no Brasil por meio de variadas habilitações devido ao caráter interdisciplinar da área e em termos da prática profissional. Ainda, a grande extensão do território nacional e as diferenças culturais, sociais e mercadológicas podem interferir na oferta de cursos de graduação.

Entre os cursos pesquisados e que possuem a informação sobre a obrigatoriedade da disciplina na estrutura curricular, constatou-se que a maioria das disciplinas sobre sustentabilidade é optativa, e em geral, oferecida na metade do curso, entre o $3^{\circ}$ e $6^{\circ}$ semestre, com carga horária entre 30 e 60 horas-aula.

\section{ANÁLISE DAS EMENTAS}

As ementas das disciplinas pesquisadas foram analisadas através da técnica de análise de conteúdo. Após a leitura, a classificação e a análise dos dados, elaboraram-se as subcategorias e a partir dos aspectos em comum foram agrupadas em macro categorias. A figura 1 ilustra as categorias que foram construídas a partir da análise realizada.

Figura 1: Categorização dos dados.

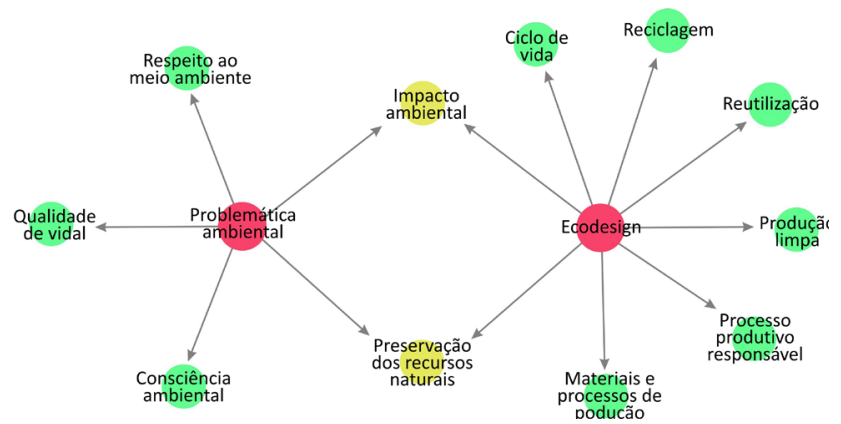

Fonte: Imagem gerada através do software RQDA (2002).
Como pode ser observado nas categorias elaboradas a partir da análise das ementas, constata-se que a abordagem da sustentabilidade nas disciplinas está relacionada com as questões da problemática ambiental e ao ecodesign. Em relação à macro categoria "problemática ambiental", são abordados os seguintes aspectos: respeito ao meio ambiente, qualidade de vida, consciência ambiental, preservação dos recursos naturais e impactos ambientais. A questão da problemática ambiental é uma preocupação atual voltada para os problemas ambientais acentuados, principalmente, a partir do período industrial do século XIX. A partir desta época, junto com os novos bens de consumo, o conforto, o bem estar do ser humano, ocorreu a acentuada degradação da natureza, a poluição, a geração de resíduos, e outros problemas ambientais, que gerou impactos sociais, ambientais e econômicos. Diante desta problemática, surgiu o conceito de desenvolvimento sustentável, o qual é mediado por um discurso que visa um ideal para os seres humanos, ou seja, o que ocorre é uma busca pelo desenvolvimento sustentável, em que são criadas estratégias e formas para considerá-lo de maneira mais eficaz, que precisa ser considerado nas esferas econômica, social e ambiental. Assim, o desenvolvimento sustentável, depende do equilíbrio entre essas dimensões, as quais são intrinsecamente interdependentes (UN DOCUMENTS, 2010).

Para Portilho (2005) até a década de 70 a crise ambiental era atribuída ao crescimento demográfico, principalmente nos países em desenvolvimento. A partir dessa década, com a realização da Conferência de Estocolmo, tornou-se explícito de que a causa da crise ambiental estava localizada, principalmente, nas nações industrializadas, nas quais o estilo de produção, seja capitalista ou socialista, requer grande quantidade de recursos e energia do planeta, gerando impacto ambiental. Assim, foi iniciado o processo de internacionalização da pauta ambiental nos meios de produção capitalistas, através de pressão governamental, estabelecimento de normas e exigências ambientais. A partir da década de 90, intensificou-se a percepção do impacto ambiental através dos altos padrões de consumo, o que repercutiu na definição da problemática ambiental estar relacionada com os altos 
padrões de consumo e estilos de vida. A partir da década de 70, a relação entre consumo e meio ambiente, está ganhando centralidade nas propostas de política ambiental internacional, tornando-se uma das principais vertentes da sustentabilidade.

Para Kazazian (2005), durante a década de 1970 o consumo humano de recursos naturais começou a ultrapassar as capacidades biológicas da terra. Em virtude disso, Ashby e Johnson (2010) comentam que surgiu a preocupação com a diminuição dos impactos ambientais, além da conscientização em relação ao projeto voltado para o meio ambiente, e ao longo prazo, para a sustentabilidade. Segundo Manzini e Vezzoli (2002), a conscientização em torno do problema ambiental repercutiu na reorientação de novos comportamentos sociais, ou seja, na busca por produtos e serviços que consideram os aspectos ambientais. De tal modo, Papanek (2002) aponta que o designer preocupa-se com o desenvolvimento de diversos produtos, e a atividade deste profissional tem influências diretas sobre a ecologia. Assim, o autor defende que o repertório das capacidades dos designers abrange "a sabedoria para prever as consequências ambientais, ecológicas, econômicas e políticas provocadas pelo design" (PAPANEK, 2002, p. 10).

Desta forma, a questão da problemática ambiental associada ao design, ocorre pelo fato de que o design vem passando por profundas mudanças no processo de desenvolvimento de produtos nos últimos anos, que transpassa a questão do produto ser esteticamente agradável, ser funcional e ter uma estrutura bem resolvida, a aplicação do fator ambiental vem sendo imposta como outro requisito de projeto (CÂNDIDO, 2011).

Em relação à macro categoria Ecodesign, são abordados os seguintes aspectos: ciclo de vida, reciclagem, reutilização, impactos ambientais, processo produtivo responsável, materiais e processos de produção e produção limpa. Para Kazazian (2005) o ecodesign é uma obordagem de projeto que visa à redução de impacto causado pelo ciclo de vida do produto, conservando sua qualidade de uso, funcionalidade e desempenho a fim de melhorar a qualidade de vida dos usuários. Dessa forma, o ecodesign consiste em uma maneira de projetar levando em consideração os critérios ecológicos com a mesma relevância dos demais requisitos projetuais. Neste sentido, a abordagem do ecodesign nas ementas pode estar associada às tendências do design a cerca da preocupação em reverter danos causados ao planeta a partir da industrialização em massa dos séculos XIX e XX, através de uma abordagem mais responsável levando em consideração a durabilidade dos produtos, produtos mais eficientes em relação ao consumo de energia, o projeto de produtos que possam ser reutilizados e reciclados, com baixo custo, economia de materiais e racionalização dos componentes (LANDIM, 2008).

A abordagem do ecodesign está relacionada com o ciclo de vida do produto na medida em que considera as possíveis implicações ambientais. De acordo com Lewis e Gertsakis (2001), a análise do ciclo de vida pode ser considerada uma importante ferramenta para o desenvolvimento de produtos que visam à sustentabilidade. Os princípios do ecodesign também abarcam a reutilização e a reciclagem de materiais, assim, no desenvolvimento de produtos, segundo Manzini e Vezzoli (2002) é importante facilitar a desmontagem, prever atualizações tecnológicas, projetar para a facilidade na troca de peças, e possibilitar a identificação de diferentes materiais.

Ainda em relação ao ecodesign, nas ementas das disciplinas constatou-se a preocupação com o uso de materiais e processos de fabricação que visam à diminuição de impactos ambientais no desenvolvimento de produto. Manzini e Vezzoli (2002) argumentam que o designer tem um papel relevante na seleção e aplicação de materiais e processos de produção a serem empregados em produtos. Além disso, o designer tem grande influência na escolha das fontes de energia para o funcionamento dos produtos. Ainda, comentam que o designer pode intervir nas fases produtivas e na distribuição do produto.

Neste contexto, a seleção de materiais pelo designer é essencial, as decisões em seu trabalho podem ter consequências ecológicas em longo prazo e de longo alcance, já que os materiais determinam várias formas de impacto ambiental, ocasionando diversos efeitos no ecossistema (PAPANEK, 2002). Dessa forma, Manzini e Vezzoli (2002) indicam uma lista de recomendações para a seleção de materiais que visa minimizar impactos ambientais:

- Evitar empregar materiais tóxicos e danosos no produto;

- Evitar adicionar aditivos que causam emissões tóxicas e danosas;

- Evitar acabamentos tóxicos e danosos;

- Evitar usar materiais que estão prestes a se esgotar;

- Usar materiais renováveis;

- Usar materiais biodegradáveis;

- Usar materiais reciclados;

- Usar materiais que procedam de refugos de processos produtivos;

- Usarcomponentesqueprocedam deprodutosjá eliminados;

- Escolher tecnologias de transformação dos materiais de baixo impacto.

Estas especificações podem guiar o designer na seleção de materiais com vistas à sustentabilidade. É visto que 
todo e qualquer material provoca algum tipo de impacto, pois como observado, os materiais passam por uma cadeia de processos que vai desde a sua extração até o processo de produção dos produtos que geram resíduos e uso de energia. Contudo, conforme as recomendações propostas é possível explorar possibilidades para minimizar os impactos provocados pelos materiais em todo o ciclo de vida dos produtos.

Cabe destacar que os princípios da sustentabilidade abordados nas ementas centram-se na problemática ambiental associada a aspectos de produtos, como materiais, processos de fabricação, ciclo de vida, reciclagem, reutilização e outros. Estes aspectos são empregados nas disciplinas sobre sustentabilidade de cursos com habilitação em produto, que são os que mais possuem disciplinas sobre sustentabilidade, como constatado anteriormente.

Portanto, os conceitos sobre sustentabilidade abordados nas ementas analisadas nesta pesquisa enfatizam o papel do designer como personagem estratégico no desenvolvimento de produtos, avaliando implicações ambientais, soluções técnicas, considerando, durante a concepção de produtos, a diminuição de impactos ambientais ligadas ao ciclo de vida do produto.

\section{CONCLUSÕES}

Nesta pesquisa constatou-se que o tema sustentabilidade vem sendo abordado nos cursos de design em diversas universidades federais brasileiras. No entanto, frente ao número de cursos de design em Instituições Federais de Ensino Superior, considera-se que poucos cursos abordam a temática da sustentabilidade na estrutura curricular, visto a importância deste assunto frente ao cenário de degradação ambiental, social e econômico vivenciado nos dias atuais. Dessa forma, o ensino da sustentabilidade é importante para que os designers conheçam e implementem no desenvolvimento de projetos e serviços os conceitos que norteiam a sustentabilidade.

Verificou-se que a abordagem da sustentabilidade nos cursos de design é realizada em disciplinas específicas abordando a problemática ambiental e as estratégias de ecodesign. Considera-se relevante que os conceitos de sustentabilidade sejam trabalhados também dentro de outras disciplinas, como as de projeto, em que o estudante tem a oportunidade de projetar levando em consideração os fatores que minimizem impactos ambientais, sociais e econômicos. Para isso, podem ser utilizadas estratégias de ecodesign, como o desenvolvimento de produto voltado para reciclagem e a reutilização, a redução de materiais, o uso de materiais locais, a escolha por processos de fabricação de baixo custo, e outros que impactem positivamente nas esferas ambiental, social e econômica abordadas na sustentabilidade.

Por fim, cabe salientar, que estas estratégias não irão solucionar os problemas ambientais acentuados a partir do período da Revolução Industrial, mas buscam minimizá-los e ao longo prazo podem repercutir em bons resultados. Assim, é necessário abordar as questões sobre a sustentabilidade nos cursos de design a fim de conscientizar os designers e apontar alternativas para que possam colocá-las em prática.

\section{REFERÊNCIAS}

ASHBY, M. F.; JOHNSON, K. Materials and design: the art and science of material selection in product design. Amsterdam: Elsevier/Butterworth-Heinemann, 2010.

BARDIN, L. Análise de conteúdo. Lisboa: Edições 70, 2011.

CÂNDIDO, L. H. A. Estudo do ciclo de reciclagem de materiais em blendas acrilonitrila-butadieno-estireno/policarbonato. Doutorado (Tese). Programa de Pós Graduação em Engenharia de Minas, Metalúrgica e de Materiais -Escola de Engenharia, Universidade Federal do Rio Grande do Sul, Porto Alegre, 2011.

DIAS, M. R. A. C. O Ensino do Design: a interdisciplinaridade na disciplina de projeto em design. Mestrado (Dissertação). Programa de Pós-Graduação em Engenharia de Produção da Universidade Federal de Santa Catarina, Florianópolis, 2004.

E-MEC. Instituições de Educação Superior e Cursos Cadastrados. Disponível em: <http://emec.mec.gov.br/> Acesso em 10 de julho de 2015.

GADOTTI, M. Educar para a sustentabilidade. Revista Inclusão Social, Brasília, v. 3 n. 1, 2008.

HATADANI, P. da S.; ANDRADE, R. R.; SILVA, J.C.P. da. Um estudo de caso sobre o ensino do Design no Brasil: $A$ Escola Superior de Desenho Industrial (ESDI). $9^{\circ}$ Congresso de Pesquisa e Desenvolvimento em Design, 2010.

KAZAZIAN, T. Haverá a idade das coisas leves: design e desenvolvimento sustentável. São Paulo: Editora Senac São Paulo, 2005.

LANDIM, P. C. Design e Designer. In: Jofre Silva. (Org.). 
Design, Arte e Tecnologia 4. São Paulo: Rosari, Universidade Anhembi Morumbi, PUC-Rio e Unesp-Bauru, 2008.

LEWIS, H.; GERTSAKIS, J. Design + environment: a global guide to designing greener goods. Sheffield: Greenleaf Publishing, 2001.

MANZINI, Ezio; VEZZOLI, Carlo. O desenvolvimento de produtos sustentáveis: os requisitos ambientais dos produtos industriais. São Paulo: Editora da Universidade de São Paulo - EDUSP, 2002.

MINISTÉRIO DAS RELAÇÕES EXTERIORES. Denominações das Instituições de Ensino Superior (IES). Disponível na internet em: <http://www.dce.mre.gov.br/nomenclatura_cursos.html> Acesso em: 23 jun. 2013.

PAPANEK, V. Arquitetura e design: ecologia e ética. Lisboa: Edições 70, 2002.

PORTILHO, F. Sustentabilidade ambiental, consumo e cidadania. São Paulo: Cortez, 2005.

RQDA. R- based qualitative data analysis. $\mathrm{R}$ package version 0.2-3. Disponível em: <http://rqda.r-forge.r-project.org/> Acesso em: 12 de novembro de 2015.

SAHTOURIS, E. Skills for the age of sustainability: An unprecedented time of opportunity. Disponível em: <http://www.ratical.org/LifeWeb/Articles/theBridge0502. html>. Acesso em 10 de janeiro de 2016.

SANTOS, A. S. Perspectiva para uma Epistemologia do Design: a abordagem de um design para a sustentabilidade como manifestação paradigmática. $9^{\circ}$ Congresso Brasileiro de Pesquisa e Desenvolvimento em Design, 2010.

SELAU, L. G.; VIEIRA, G. B. B. Ensino do design: panorama dos diferentes cursos de design no Brasil. $11^{\circ}$ Congresso Brasileiro de Pesquisa e Desenvolvimento em Design, 2014.

UFAM. Universidade Federal do Amazonas. Disponível em: < http://www.ufam.edu.br/ > Acesso em 5 de outubro de 2015.

UFCA. Universidade Federal do Cariri. Disponível em: <http://www.ufca.edu.br/portal/> Acesso em 5 de outubro de 2015.
UFF. Universidade Federal Fluminense. Disponível em: <http://www.uff.br/> Acesso em 5 de outubro de 2015.

UFG. Universidade Federal de Goiás. Disponível em: <https://www.ufg.br/> Acesso em 5 de outubro de 2015.

UFMA. Universidade Federal do Maranhão. Disponível em: < http://portais.ufma.br/PortalUfma/index.jsf $>$ Acesso em 5 de outubro de 2015 .

UFMG. Universidade Federal de Minas Gerais. Disponível em: <https://www.ufmg.br/> Acesso em 5 de outubro de 2015.

UFPR. Universidade Federal do Paraná. Disponível em: < http://www.ufpr.br/portalufpr/ > Acesso em 5 de outubro de 2015.

UFRGS. Universidade Federal do Rio Grande do Sul. Disponível em: <http://site.ufsm.br/> Acesso em 5 de outubro de 2015.

UFRN.UniversidadeFederaldoRioGrandedoNorte. Disponível em: < http://www.sistemas.ufrn.br/portal/ PT/;jsessionid=CFC8B96B9ED47E7654F8078CE947AADA. sistemas2bi1> Acesso em 5 de outubro de 2015.

UFSC.UniversidadeFederaldeSanta Catarina.Disponível em: <http://ufsc.br/> Acesso em 5 de outubro de 2015.

UFSM. Universidade Federal de Santa Maria. Disponível em: <http://site.ufsm.br/> Acesso em 5 de outubro de 2015.

UNB. Universidade de Brasília. Disponível em: < http://www.unb.br/> Acesso em 5 de outubro de 2015.

UN DOCUMENTS. Report of the World Commission on Environment and Development: our common future. Disponível em: <http://www.un-documents.net/ wced-ocf.htm>. Acesso em: 12 dez. 2012.

VALLEI, C. Bacharelado ou Licenciatura? In: e-Guia do Estudante - Abril. 2012. Disponível na internet em: <http:// guiadoestudante.abril.com.br/vestibular-enem/bacharelado-ou-licenciatura-697319.shtml> Acesso em: 23 jun. 2013.

WOLLNER, A. Textos recentes e escritos históricos. São Paulo: Rosari, 2002. 